\title{
A meta-analysis and systematic review: adjuvant interferon therapy for patients with viral hepatitis- related hepatocellular carcinoma
}

\author{
Shaojie Jiang ${ }^{1 *}$, Yingxia Liu², Linhai Wang ${ }^{1}$, Chenyang Duan³ and Mengying Liu ${ }^{4}$
}

\begin{abstract}
Objective: To evaluate the efficacy and safety of adjuvant IFN therapy for viral hepatitis-related hepatocellular carcinoma (HCC) after treatment with surgical resection or transarterial chemoembolization (TACE).

Methods: Controlled trials of adjuvant treatment with IFN for patients with HCC published between 2000 and 2012 were searched electronically in MEDLINE, PubMed, Cochrane Library, and EMBASE databases. According to the heterogeneity of the studies, two different models - the fixed-effect model and the random-effect model - were applied to analyze the results.

Results: Ten trials were screened according to inclusion and exclusion standards. Eight randomized, controlled trials and two non-randomized, controlled trials were included. These ten trials with a total of 1,029 subjects were eventually involved in the meta-analysis; $528 \mathrm{HCC}$ patients were treated with adjuvant treatment with IFN and 501 patients with placebo. Compared to the control group, the recurrence rates of HCC in IFN group were significantly lower (odds ratio $(O R)=0.66 ; 95 \%$ confidence interval $(C l)=0.50$ to $0.86 ; P=0.02$ ), especially after TACE treatment according to subgroup analysis $(\mathrm{OR}=0.73 ; 95 \% \mathrm{Cl}=0.52$ to $1.01 ; P=0.06$ for surgical resection; and $\mathrm{OR}=0.54$; $95 \% \mathrm{Cl}=0.33$ to $0.86, P=0.01$ for TACE). The death rates in the IFN group also significantly decreased according to not only total events analysis $(\mathrm{OR}=0.42 ; 95 \% \mathrm{Cl}=0.32$ to $0.56 ; P<0.00001)$ but also subgroup analysis $(\mathrm{OR}=0.51$; $95 \% \mathrm{Cl}=0.36$ to $0.72 ; P=0.0002$ for surgical resection; and $\mathrm{OR}=0.33 ; 95 \% \mathrm{Cl}=0.21$ to $0.50 ; P<0.00001$ for TACE).

Conclusions: Adjuvant IFN therapy may significantly reduce the recurrence rates of patients with viral hepatitisrelated HCC and improve the survival of patients after surgical resection or TACE. The ideal dose mostly selected is $3 \mathrm{MIU} / \mathrm{ml}$, three times per week, which can make patients tolerate the adverse reactions of IFN better and maintain effective concentrations for a long time.
\end{abstract}

Keywords: Interferon, Adjuvant treatment, Viral hepatitis, Hepatocellular carcinoma, Meta-analysis

\section{Review}

\section{Introduction}

Primary liver cancer, which consists predominantly of hepatocellular carcinoma (HCC), is the fifth most common cancer worldwide and the third most common cause of cancer mortality [1]. Due to the high degree of malignancy and the difficulty of diagnosis in the early stage, the lesions of most patients have already metastasised when they first see a doctor [2]. However, only approximately 10 to $30 \%$

\footnotetext{
* Correspondence: jiangshaojie130916@163.com

'Department of Hepatobiliary Surgery, Shenyang Military Region General Hospital, Shenhe District in Shenyang culture road no. 83, Shenyang 110015, China

Full list of author information is available at the end of the article
}

of patients may have the opportunity to receive radical therapies such as liver transplantation [3], but liver transplantation is only suitable for a small group of patients because of its high cost and strict selection criteria. Therefore, most patients receive surgical resection or transarterial chemoembolization (TACE) treatment [4]. Unfortunately, the recurrence rate of HCC 3 years after pure surgical resection or TACE is more than $50 \%$, which is also the main cause of death after treatment [5]. As we know, most HCC patients carry the hepatitis B virus (HBV) and the hepatitis $\mathrm{C}$ virus (HCV). Since IFN can inhibit the replication of $\mathrm{HBV}$ and $\mathrm{HCV}$ and also kill the cancer cells, several researchers believe IFN may reduce

\section{Biomed Central}


the recurrence of $\mathrm{HCC}$ in patients after treatment $[6,7]$. But the conclusion is not consistent [6-8]. This paper raised clinical data through a Cochrane system evaluation, and used fixed/random effect models to perform a metaanalysis in order to study the therapeutic effects of radiofrequency ablation and hepatic resection in the treatment of small HCC, and provide a basis for evidencebased medicine.

\section{Methods}

\section{Search strategy}

\section{Literature search}

We reviewed all studies reporting the results of trials on the therapeutic effects of adjuvant treatment with IFN for patients with hepatocellular carcinoma (HCC). Computerized literature searches of MEDLINE, PubMed, Cochrane Library, and EMBASE databases, from 2000 to 2012, were undertaken. Search terms used were 'hepatocellular carcinoma', 'liver cancer', 'liver neoplasm', 'interferon', and 'IFN'. These terms were used in different combinations with each other. In addition, we reviewed the reference lists of the original articles and reviews on the topic to identify other possible eligible trials.

\section{Study selection}

The inclusion criteria for this meta-analysis were as follows: (1) all cases were diagnosed as HCC through pathology tests and combined with viral hepatitis (HBV/ $\mathrm{HCV}$ ); (2) both the IFN group and control group were treated with surgical resection or TACE; (3) adjuvant treatment with IFN lasted more than 3 months after the first treatment (surgical resection or TACE); (4) followup time was greater than 1 year, and the control group was treated with placebo; (5) the study subjects are all controlled clinical trial cases; (6) sample size greater than 20 cases.

The exclusion criteria for this meta-analysis were as follows: (1) metastatic hepatic carcinoma or recurrent liver cancers that have already been treated; (2) full text of the trial was not available; (3) when multiple publications from a single institution/author appeared to include duplication of patients, the study with smaller patient group was excluded; (4) follow-up time less than 1 year; (5) sample size $\leq 20$ cases.

\section{Data extraction}

All literature searches were independently reviewed by two authors (CD and ML) to identify relevant trials that met the inclusion criteria and were checked by an independent reviewer. Disparities were resolved by discussion and mailed to the authors for explanation.

Included studies were reviewed based on the random fashion method, blind method and lost to follow-ups of the allocation plan. The grades to the creditability of the studies were divided into three grades according to Cochrane system evaluation handbook [9]: Grade A cases met all evaluated standards and had correct methodology, which gave a low risk of bias; Grade B cases did not describe one or several standards, which gave a moderate risk of bias; Grade $\mathrm{C}$ cases had one or several standards incorrect, which gave a high risk of bias. The methodology quality evaluations gave two studies as Grade A and eight studies as Grade B. Study quality was independently assessed by two reviewers (Table 1).

\section{Data analysis}

Statistical analyses were performed using Review Manager Software (RevMan 5.2; Cochrane Collaboration, Oxford, UK). Continuous descriptive data of the IFN group and the control group were reported as the mean \pm standard deviation and dichotomous data were recorded as the case number (n).

The Mantel-Haenszel Q-statistic was used to assess heterogeneity among the studies and the $\mathrm{I}^{2}$ statistic was computed to examine the proportion of total variation in the study estimate due to heterogeneity. We considered $P>0.10$ or $P \leq 0.10, I^{2} \leq 50 \%$ to indicate no significant heterogeneity between the trials and selected a fixed-effect model to perform analysis. Furthermore, we considered $P \leq 0.10, I^{2}>50 \%$ to indicate significant heterogeneity and used a random-effect model to perform analysis. The integration results regarded $P<0.05$ as the standard for statistical significance.

Extensive effort was made to remove all duplicated data and to include all studies published to date. Publication bias in outcomes was assessed and treated using standard methodology. Funnel plots were used to visually inspect the relationship between sample size and treatment effects for the two groups.

\section{Results}

\section{Search results}

A total of 403 relevant articles were identified in a combined search of MEDLINE, PubMed, Cochrane Library and EMBASE databases, from 2000 to 2012, and by a manual approach (search of studies cited in previous reviews and of reference lists from the identified articles); 368 articles were excluded because they were not relevant for the purpose of this meta-analysis through scanning the title/abstract. Full-length articles could not be retrieved for 14 of the 35 accepted articles for various reasons. Of the 21 full articles retrieved, 11 articles were excluded (see Figure 1 for the reasons). Eventually, 10 articles with a total of 1,029 subjects were included in the systematic review, including eight randomized, controlled trials and two non-randomized, controlled trials (Figure 1). 
Table 1 Assessment quality of included studies

\begin{tabular}{|c|c|c|c|c|c|c|c|}
\hline Study & Trial type & Randomization & allocation concealment & Blinding & Lost of follow up & ITT & Grade \\
\hline Kubo S (2002) [9] & $\mathrm{RCT}$ & Adequate & Unclear & Adequate & Yes & Yes & $B$ \\
\hline Shiratori Y (2003) [10] & $\mathrm{RCT}$ & Adequate & Adequate & Adequate & Yes & Yes & A \\
\hline Lin SM (2004) [11] & $\mathrm{RCT}$ & Unclear & Unclear & Unclear & Yes & Yes & B \\
\hline Piao CY (2005) [12] & RCT & Adequate & Unclear & Adequate & Yes & Yes & B \\
\hline Mazzaferro V (2006) [13] & $\mathrm{RCT}$ & Adequate & Unclear & Unclear & Yes & Yes & B \\
\hline Sun HC (2006) [14] & $\mathrm{RCT}$ & Adequate & Adequate & Adequate & Yes & Yes & A \\
\hline Lo CM (2007) [15] & $\mathrm{RCT}$ & Adequate & Adequate & Unclear & Yes & Yes & B \\
\hline Li M (2009) [16] & $\mathrm{RCT}$ & Adequate & Unclear & Unclear & Yes & Yes & B \\
\hline Li N (2010) [17] & NRCT & Adequate & Adequate & Unclear & Yes & Yes & B \\
\hline Ishikawa (2012) [18] & NRCT & Adequate & Unclear & Unclear & Yes & Yes & B \\
\hline
\end{tabular}

A total of 1,029 subjects were eventually included in the meta-analysis: $528 \mathrm{HCC}$ patients were treated with adjuvant treatment with IFN and 501 patients with placebo. The longest follow-up time was 85.2 months and the shortest follow-up time was 24.0 months. The largest sample size was 236 and the smallest size was 30 . The characteristics of the 10 studies included in the metaanalysis arre listed in Table 2 and the applications of adjuvant treatment with IFN in the IFN group are listed in Table 3.

\section{Meta-analysis}

We primarily compared recurrence rates and death rates for HCC between radiofrequency ablation (RFA) and

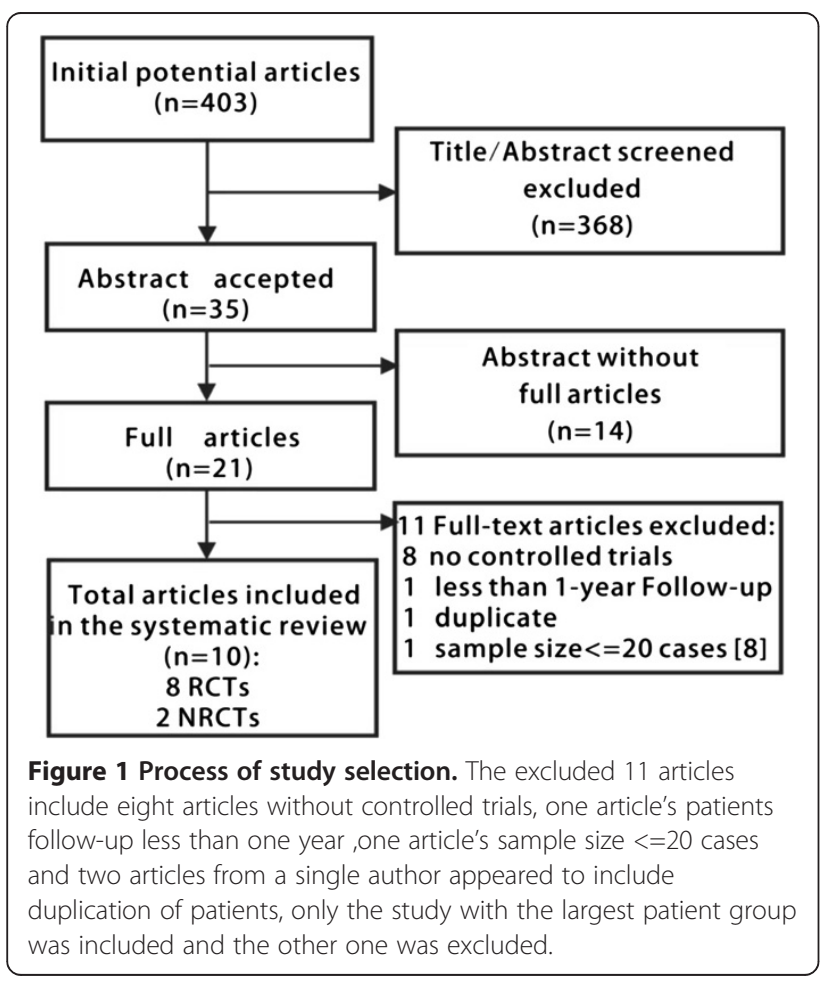

hepatic resection (HR) in the treatment of small HCC. In order to further detect if there are any difference in recurrence rates and death rates based on the different treatment types, we performed subgroup analysis based on the treatment type (surgical resection/TACE). The results of meta-analysis for each indicator are listed below.

\section{Recurrence rates for hepatocellular carcinoma}

Nine studies including 975 cases [9-17] compared the IFN group and the control group with regard to the recurrence rates of $\mathrm{HCC}$. Taking the odds ratio (OR) as an indicator of the effect of measures, we performed a $X^{2}$ test to examine the heterogeneity; the result was $P=0.67(>0.10), \mathrm{I}^{2}=0 \%(<50 \%)$, which indicated that there was no heterogeneity between the two groups. Therefore, we used a fixed-effect model to perform a meta-analysis. The results $(\mathrm{OR}=0.66 ; 95 \%$ confidence interval $(\mathrm{CI})=0.50$ to $0.86, P=0.02)$ indicated that adjuvant treatment with IFN might significantly decrease the recurrence rates of $\mathrm{HCC}$ after initial treatment.

In order to further reinforce the conclusion above, we performed subgroup analysis based on the treatment type (surgical resection/TACE). We performed a $X^{2}$ test to examine the heterogeneity; the results were $P=0.60$ (>0.10), $\mathrm{I}^{2}=0 \%(<50 \%)$ and $P=0.57(>0.10), \mathrm{I}^{2}=0 \%$ $(<50 \%)$, respectively, which indicated that there was no heterogeneity. Therefore, we used a fixed-effect model. The results $(\mathrm{OR}=0.73 ; 95 \% \mathrm{CI}=0.52$ to $1.01 ; P=0.06$ for surgical resection; and $\mathrm{OR}=0.54 ; 95 \% \mathrm{CI}=0.33$ to $0.86 ; P=0.01$ for TACE) indicated that there was a significant difference between the IFN group after TACE treatment and the control group for recurrence of HCC, and there was no difference between the IFN group after surgical resection and the control group (Figure 2).

\section{Death rates for hepatocellular carcinoma}

Nine studies including 949 cases [9-11,13-18] compared the IFN group and the control group with regard to the 
Table 2 Characteristics of the studies included in the meta-analysis

\begin{tabular}{|c|c|c|c|c|c|c|c|c|c|c|}
\hline Study & Group & Cases & $\begin{array}{l}\text { Average } \\
\text { age (ys) }\end{array}$ & $\begin{array}{c}\text { Male } \\
\text { rate (\%) }\end{array}$ & $\begin{array}{c}\text { Tumor } \\
\text { size }(\mathrm{cm})\end{array}$ & $\begin{array}{c}\text { No. of } \\
\text { tumor } \geq 2 \text { (\%) }\end{array}$ & $\begin{array}{c}\text { Cirrhosis } \\
(\%)\end{array}$ & $\begin{array}{c}\text { Child-Pugh } \\
(\%, A / B)\end{array}$ & $\begin{array}{c}\text { Hepatic } \\
\text { virus }\end{array}$ & Therapy \\
\hline \multirow[t]{2}{*}{ Kubo S (2002) } & Interferon & 15 & 61.9 & 100.0 & 2.5 & 0 & 46.7 & $73.3 / 26.7$ & $\mathrm{HCV}$ & Surgical resection \\
\hline & Placebo & 15 & 60.0 & 100.0 & 2.6 & 0 & 52.2 & $80.0 / 20.0$ & & \\
\hline \multirow[t]{2}{*}{ Shiratori Y (2003) } & Interferon & 49 & 61.0 & 71.4 & 2.2 & 34.7 & 100.0 & - & $\mathrm{HCV}$ & Surgical resection \\
\hline & Placebo & 25 & 63.0 & 68.0 & 2.3 & 36.0 & 100.0 & - & & \\
\hline \multirow[t]{2}{*}{ Lin SM (2004) } & Interferon & 20 & 61.5 & 80.0 & 2.2 & 15.0 & 90.0 & $85.0 / 15.0$ & $\mathrm{HBV} / \mathrm{HCV}$ & TACE \\
\hline & Placebo & 10 & 59.0 & 70.0 & 2.5 & 20.0 & 100.0 & $90.0 / 10.0$ & & \\
\hline \multirow[t]{2}{*}{ Piao CY (2005) } & Interferon & 30 & 59 & 76.7 & 2.3 & 23.3 & 13.0 & $60.0 / 36.7$ & $\mathrm{HBV} / \mathrm{HCV}$ & Ablation/TACE/ \\
\hline & Placebo & 40 & 58 & 72.5 & 2.5 & 17.5 & 23.0 & $55.0 / 42.5$ & & \\
\hline \multirow[t]{2}{*}{ Mazzaferro V (2006) } & Interferon & 76 & 65.0 & 80.3 & 3.4 & 22.4 & 94.0 & $92.1 / 7.9$ & $\mathrm{HCV}$ & Surgical resection \\
\hline & Placebo & 74 & 67.0 & 68.9 & 3.2 & 25.7 & 88.0 & $94.6 / 5.4$ & & \\
\hline \multirow[t]{2}{*}{ Sun HC (2006) } & Interferon & 118 & 52.2 & 89.8 & 4.3 & 13.6 & 83.1 & - & HBV & Surgical resection \\
\hline & Placebo & 118 & 50.4 & 86.4 & 4.9 & 12.7 & 88.1 & - & & \\
\hline \multirow[t]{2}{*}{ Lo CM (2007) } & Interferon & 40 & 49.0 & 77.5 & 5.5 & 17.5 & 47.5 & - & $\mathrm{HBV} / \mathrm{HCV}$ & Surgical resection \\
\hline & Placebo & 40 & 54.0 & 85.0 & 5.7 & 27.5 & 47.5 & - & & \\
\hline \multirow[t]{2}{*}{ Li M (2009) } & Interferon & 108 & 50.3 & 71.3 & 4.9 & 54.6 & 100.0 & $90.7 / 9.3$ & HBV & TACE \\
\hline & Placebo & 108 & 49.2 & 68.5 & 4.8 & 54.6 & 100.0 & $91.7 / 8.3$ & & \\
\hline \multirow[t]{2}{*}{ Li N (2010) } & Interferon & 43 & 53.2 & 72.5 & 3.2 & 37.2 & 88.0 & $85.0 / 15.0$ & HBV & TACE \\
\hline & Placebo & 36 & 51.2 & 71.3 & 3.4 & 37.2 & 88.0 & $85.0 / 15.0$ & & \\
\hline \multirow[t]{2}{*}{ Ishikawa (2012) } & Interferon & 29 & 59.0 & 83.2 & 2.3 & 13.5 & 100.0 & - & $\mathrm{HCV}$ & TACE \\
\hline & Placebo & 25 & 58.7 & 81.2 & 2.5 & 17.4 & 100.0 & - & & \\
\hline
\end{tabular}

Abbreviation: TACE trans-catheter arterial chemoembolization.

death rates of HCC. Taking OR as an indicator of the effect of measures, we performed a $x^{2}$ test to examine the heterogeneity; the result was $P=0.54(>0.10), \mathrm{I}^{2}=$ $0 \%(<50 \%)$, which indicated that there was no heterogeneity between the two groups. Therefore, we used a fixedeffect model to perform a meta-analysis. The results $(\mathrm{OR}=0.42 ; 95 \% \mathrm{CI}=0.32$ to $0.56, P<0.00001)$ indicated that adjuvant treatment with IFN might significantly decrease the death rates of HCC after initial treatment.

In order to further reinforce the conclusion above, we performed subgroup analysis based on the treatment type (surgical resection/TACE). We performed a $\chi^{2}$ test to examine the heterogeneity; the results were $P=0.91$ $(>0.10), \mathrm{I}^{2}=0 \%(<50 \%)$ and $P=0.29(>0.10), \mathrm{I}^{2}=19 \%$ $(<50 \%)$, respectively, which indicated that there was no

Table 3 Applications of adjuvant treatment with interferon in IFN group

\begin{tabular}{|c|c|c|}
\hline Study & Intervention & Follow-up (months) \\
\hline Ikeda K (2000) & 10 patients received natural IFN- $\beta 6 \times 10^{6}$ twice a week for 36 months & 25.0 \\
\hline Kubo S (2000) & $\begin{array}{l}15 \text { patients received } 6 \times 10^{6} \text { IFN-a intramuscularly every day for } 2 \text { weeks, } \\
\text { then three times weekly for } 14 \text { weeks, and finally twice weekly for } 88 \text { weeks. }\end{array}$ & 60.0 \\
\hline Shiratori Y (2003) & 49 patients received $6 \times 10^{6} \mathrm{IFN}-\mathrm{a}$ intramuscularly three times weekly for 48 weeks. & 85.2 \\
\hline Lin SM (2004) & 20 patients received $3 \times 10^{6} \mathrm{IFN}-\mathrm{a} 2 \mathrm{~b}$ intramuscularly three times weekly for 24 months. & 27.0 \\
\hline Piao CY (2005) & 30 patients orally received 100 mg of lamivudine daily after HCC treatment. & 24.0 \\
\hline Mazzaferro V (2006) & 76 patients received $3 \times 10^{6} \mathrm{IFN}-\mathrm{a} 2 \mathrm{~b}$ three times weekly for 48 weeks. & 45.0 \\
\hline Sun HC (2006) & $\begin{array}{c}118 \text { patients received } 3 \times 10^{6} \mathrm{IFN} \text {-a intramuscularly twice a week for } 2 \text { weeks and } \\
\text { then } 5 \times 10^{6} \text { three times weekly for } 18 \text { months. }\end{array}$ & 36.5 \\
\hline Lo CM (2007) & 40 patients received $10 \times 10^{6} / \mathrm{m}^{2}$ IFN-a 2 b subcutaneously three times weekly for 16 weeks. & 30.0 \\
\hline Li M (2009) & 108 patients received IFN-a $2 \mathrm{~b} 3 \times 10^{6}$ three times weekly by intramuscular injection one week. & 24.8 \\
\hline Li N (2010) & 43 patients received lamivudine with or without adefovir dipivoxil. & 24.0 \\
\hline Ishikawa (2012) & 29 patients received PEG-IFN a-2b/ribavirin after curative HCC treatment. & 36.0 \\
\hline
\end{tabular}


heterogeneity. Therefore, we used a fixed-effect model. The results $(\mathrm{OR}=0.51 ; 95 \% \mathrm{CI}=0.36$ to $0.72 ; P=$ 0.0002 for surgical resection; and $\mathrm{OR}=0.33 ; 95 \% \mathrm{CI}=$ 0.21 to $0.50 ; P<0.00001$ for TACE) indicated that there was a significant difference between the IFN group and the control group whether after surgical resection or TACE treatment in the death rates of HCC (Figure 3).

\section{Sensitivity analysis and publication bias}

We used fixed/random-effect models to test each indicator and the results were correlated with each other. We made a funnel plot for each comparison (Figure 4), including the subgroup comparisons. The characters of both plots were basically inverted funnel-shaped, with bilateral symmetry, which indicated that there was no publication bias and the conclusions were reliable.

\section{Discussion}

This meta-analysis evaluates the efficacy and safety of adjuvant IFN therapy for viral hepatitis-related HCC after treatment by surgical resection or TACE. All cases were combined with viral hepatitis (HBV/HCV). The results of the meta-analysis showed that there was a significant difference between the IFN group and the control group both in the recurrence rates and death rates of HCC. In our clinical work, the main treatment method for HCC is surgery and TACE [19]. In order to exclude bias caused by treatment methods, we selected
HCC treated by surgery and TACE rather than other curative treatments. We performed subanalysis between surgical resection and TACE to ascertain any difference between these two methods.

Only two included studies reported the adverse events of adjuvant IFN therapy $[11,15]$. The major adverse events were high fever, tiredness, a decrease in white cells and platelets, hepatotoxicity and hyperthyroidism, and so forth. The adverse events of IFN depend on the dose. Randomized, controlled trials reported by Lo and colleagues [15] were divided into a low-dose IFN group, a high-dose IFN group, and a control group. All the high-dose group (30 MIU/ml, three times per week) patients withdrew because of adverse events. The study by Sakaguchi and colleagues [20] also showed that longterm low-dose adjuvant IFN therapy could improve patient tolerance, which may improve the prognosis of treatment.

IFN has a variety of biological functions, such as antivirus, resistance to cell proliferation, anti-angiogenesis and immune adjustment, and so forth, and has been widely applied in many kinds of diseases $[21,22]$. Experiments in vitro [23] showed that IFN- $\alpha$ could restrain the proliferation of human umbilical vein endothelial cells and its inhibition function was enhanced as the dose and action time were extended. Experiments in vivo [24] showed that the tumor diameter reduced significantly after adjuvant IFN- $\alpha$ treatment and microvascular 
density was significantly lower than in the control group. We can speculate that IFN- $\alpha$ realizes its anti-tumor effects by inhibiting tumor angiogenesis and resisting cell proliferation. The biological characteristics above may explain the benefit of adjuvant IFN therapy on $\mathrm{HCC}$ patients.

Many researchers have found that the efficacy of IFN on inducing Hepatitis Be Antigen (HBeAg) seroconversion is far from satisfactory [25], but we should realize that IFN acted mainly as an antiviral, immunomodulatory and antiproliferative agent and not as an inhibitor of the integration of HBV DNA [26]. IFN therapy improves overall survival through relieving active hepatitis, improving hepatic fibrosis and liver function [27] as well as decreasing the severity of a recurrent tumor and thus be amenable to secondary curative ablation or resection [28]. From the
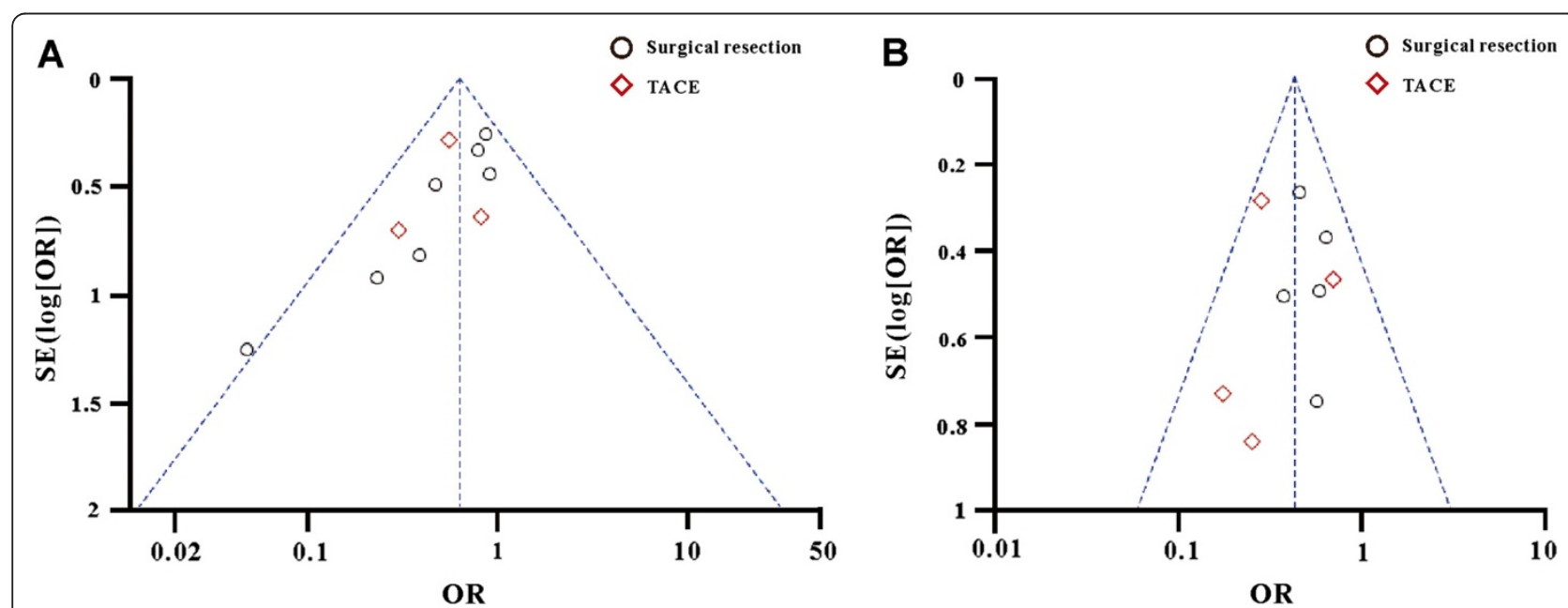

Figure 4 Funnel plot for each comparisons. A. Recurrence rate of HCC; $\mathbf{B}$. Death rates of HCC; black circle represented surgical resection; red square represented TACE treatment for HCC. 
above, we can conclude that, although IFN does not prevent recurrence in HBV-related HCC patients, it still shows long-term beneficial effects in HBV-related HCC in other ways.

This study has the following limitations: (1) although most of the included studies are randomized, controlled trials, the sample sizes are relatively small; (2) the basic characteristics of included cases are not all the same, and the effect factors to prognosis of HCC include clinical stage, pathological type, treatment methods, the size of tumor and the body's immune ability, which may also affect the results of meta-analysis; (3) the included studies report mostly on the recurrence rate and death rate; there are less reports on overall survival and disease-free survival of adjuvant IFN therapy to HCC.

\section{Conclusion}

In conclusion, the meta-analysis based on 10 included studies indicates that adjuvant IFN therapy may significantly reduce the recurrence rates of patients with viral hepatitis-related HCC and improve the survival of patients after the treatment of surgical resection or TACE. The ideal dose mostly selected is $3 \mathrm{MIU} / \mathrm{ml}$, three times per week, which can make patients tolerate the adverse reactions of IFN better and maintain an effective concentration for a long time because of IFN dose dependence.

\section{Abbreviations}

Cl: Confidence interval; HBV: Hepatitis B virus; HCC: Hepatocellular carcinoma; HCV: Hepatitis C virus; IFN: Interferon; OR: Odds ratio; TACE: Transarterial chemoembolization.

\section{Competing interests}

The authors declare that they have no competing interests.

\section{Authors' contributions}

$\mathrm{SJ}$ independently searched references and extracted the parameters from each study, took charge of data statistics and drafted the manuscript. YL independently searched references and extracted the parameters from each study. LW participated in the discussion of the discrepancies between the two reviewers. CD independently searched references and extracted the parameters from each study and revised the manuscript. ML participated in the manuscript revision. All authors read and approved the final manuscript.

\section{Author details}

'Department of Hepatobiliary Surgery, Shenyang Military Region General Hospital, Shenhe District in Shenyang culture road no. 83, Shenyang 110015, China. ${ }^{2}$ Department of Stomatology, Shenyang Military Region General Hospital, Shenyang, Liaoning 110015, China. ${ }^{3}$ Company Five of Cadet Brigade, Third Military Medical University, Chongqing 400038, China. ${ }^{4}$ Company Two of Cadet Brigade, Third Military Medical University, Chongqing 400038, China.

Received: 15 June 2013 Accepted: 5 September 2013 Published: 24 September 2013

\section{References}

1. El-Serag HB, Rudolph KL: Hepatocellular carcinoma: epidemiology and molecular carcinogenesis. Gastroenterol 2007, 132(7):2557-2576.

2. Llovet JM, Burroughs A, Bruix J: Hepatocellular carcinoma. Lancet 2003, 362(9399):1907-1917.

3. Paquet KJ, Koussouris P, Mercado MA, Kalk JF, Müting D, Rambach W: Limited hepatic resection for selected cirrhotic patients with hepatocellular or cholangiocellular carcinoma: a prospective study. Br J Surg 1991, 78(4):459-462.

4. Fan ST, Lo CM, Liu CL, Lam CM, Yuen WK, Yeung C, Wong J: Hepatectomy for hepatocellular carcinoma: toward zero hospital deaths. Ann Surg 1999, 229(3):322-330.

5. Llovet JM, Schwartz M, Mazzaferro V: Resection and liver transplantation for hepatocellular carcinoma. Semin Liver Dis 2005, 25(2):181-200.

6. von Marschall Z, Scholz A, Cramer T, Schäfer G, Schirner M, Oberg K, Wiedenmann B, Höcker M, Rosewicz S: Effects of interferon alpha on vascular endothelial growth factor gene transcription and tumor angiogenesis. J Natl Cancer Inst 2003, 95(6):437-448.

7. Wang L, Wu WZ, Sun HC, Wu XF, Qin LX, Liu YK, Liu KD, Tang ZY: Mechanism of interferon alpha on inhibition of metastasis and angiogenesis of hepatocellular carcinoma after curative resection in nude mice. J Gastrointest Surg 2003, 7(5):587-594.

8. Ikeda K, Arase Y, Saitoh S, Kobayashi M, Suzuki Y, Suzuki F, Tsubota A, Chayama K, Murashima N, Kumada H: Interferon beta prevents recurrence of hepatocellular carcinoma after complete resection or ablation of the primary tumor - a prospective randomized study of hepatitis $\mathrm{C}$ virusrelated liver cancer. Hepatol 2000, 32(2):228-232.

9. Kubo S, Nishiguchi S, Hirohashi K, Tanaka H, Shuto T, Kinoshita H: Randomized clinical trial of long-term outcome after resection of hepatitis $C$ virus-related hepatocellular carcinoma by postoperative interferon therapy. Br J Surg 2002, 89(4):418-422.

10. Shiratori $Y$, Shiina S, Teratani T, Imamura M, Obi S, Sato S, Koike Y, Yoshida $\mathrm{H}$, Omata M: Interferon therapy after tumor ablation improves prognosis in patients with hepatocellular carcinoma associated with hepatitis $C$ virus. Ann Intern Med 2003, 138(4):299-306.

11. Lin SM, Lin CJ, Hsu CW, Tai DI, Sheen IS, Lin DY, Liaw YF: Prospective randomized controlled study of interferon-alpha in preventing hepatocellular carcinoma recurrence after medical ablation therapy for primary tumors. Cancer 2004, 100(2):376-382.

12. Piao CY, Fujioka S, Iwasaki Y, Fujio K, Kaneyoshi T, Araki Y, Hashimoto K, Senoh T, Terada R, Nishida T, Kobashi H, Sakaquchi K, Shiratori Y: Lamivudine treatment in patients with HBV-related hepatocellular carcinoma - using an untreated, matched control cohort. Acta Med Okayama 2005, 59(5):217-224.

13. Mazzaferro V, Romito R, Schiavo M, Mariani L, Camerini T, Bhoori S, Capussotti L, Calise F, Pellicci R, Belli G, Tagger A, Colombo M, Bonino F, Majno P, Llovet JM, HCC Italian Task Force: Prevention of hepatocellular carcinoma recurrence with alpha-interferon after liver resection in HCV cirrhosis. Hepatol 2006, 44(6):1543-1554.

14. Sun $H C$, Tang ZY, Wang L, Qin LX, Ma ZC, Ye QH, Zhang BH, Qian YB, Wu ZQ, Fan J, Zhou XD, Zhou J, Qiu SJ, Shen YF: Postoperative interferon alpha treatment postponed recurrence and improved overall survival in patients after curative resection of HBV-related hepatocellular carcinoma: a randomized clinical trial. J Cancer Res Clin Oncol 2006, 132(7):458-465.

15. Lo CM, Liu CL, Chan SC, Lam CM, Poon RT, Ng IO, Fan ST, Wong J: A randomized, controlled trial of postoperative adjuvant interferon therapy after resection of hepatocellular carcinoma. Ann Surg 2007, 245(6):831-842.

16. Li M, Lu C, Cheng J, Zhang J, Cao C, Xu J, Xu J, Pan H, Zhong B, Tucker S, Wang D: Combination therapy with transarterial chemoembolization and interferon-alpha compared with transarterial chemoembolization alone for hepatitis B virus related unresectable hepatocellular carcinoma. J Gastroenterol Hepatol 2009, 24(8):1437-1444.

17. Li N, Lai EC, Shi J, Guo WX, Xue J, Huang B, Lau WY, Wu MC, Cheng SQ: A comparative study of antiviral therapy after resection of hepatocellular carcinoma in the immune-active phase of hepatitis B virus infection. Ann Surg Oncol 2010, 17(1):179-185.

18. Ishikawa T, Higuchi K, Kubota T, Seki K, Honma T, Yoshida T, Kamimura T: Combination PEG-IFN a-2b/ribavirin therapy following treatment of hepatitis $\mathrm{C}$ virus-associated hepatocellular carcinoma is capable of improving hepatic functional reserve and survival. Hepatogastroenterology 2012, 59(114):529-532.

19. Marrero JATM: Current Treatment Approaches in HCC. Clin Adv Hematol Oncol 2013, 5(4):15-18

20. Sakaguchi Y, Kudo M, Fukunaga T, Minami Y, Chung H, Kawasaki T: Lowdose, long-term, intermittent interferon-alpha- $2 \mathrm{~b}$ therapy after radical treatment by radiofrequency ablation delays clinical recurrence in 
patients with hepatitis $\mathrm{C}$ virus-related hepatocellular carcinoma. Intervirology 2005, 48(1):64-70.

21. Chen RY, Bowden S, Desmond PV, Dean J, Locarnini SA: Effects of interferon alpha therapy on the catalytic domains of the polymerase gene and basal core promoter, precore and core regions of hepatitis $B$ virus. J Gastroenterol Hepatol 2003, 18(6):630-637.

22. Li J, Liu K, Liu Y, Xu Y, Zhang F, Yang H, Liu J, Pan T, Chen J, Wu M, Zhou X, Yuan Z: Exosomes mediate the cell-to-cell transmission of IFN-a-induced antiviral activity. Nat Immunol 2013, 14(8):793-803.

23. Wang CJ, Xiao CW, You TG, Zheng YX, Gao W, Zhou ZQ, Chen J, Xue XB, Fan J, Zhang H: Interferon-alpha enhances antitumor activities of oncolytic adenovirus-mediated IL-24 expression in hepatocellular carcinoma. Mol Cancer 2012, 11(1):31.

24. Wang $L$, Tang $Z Y$, Qin $L X, W u X F$, Sun $H C$, Xue $Q$, Ye SL: High-dose and long-term therapy with interferon-alfa inhibits tumor growth and recurrence in nude mice bearing human hepatocellular carcinoma xenografts with high metastatic potential. Hepatol 2000, 32(1):43-48

25. Ji YJ, Li FF, Ren WH, Zhu YH, Qin CY: Quantifiable changes in HBeAg expression predict therapeutic efficacy of peg-interferon alfa-2a in patients with HBeAg-positive chronic hepatitis B. Zhonghua Gan Zang Bing Za Zhi 2013, 21(5):335-339.

26. Ormeci N: Short- and long-term effects of treatment of chronic hepatitis B and delta virus by IFN. Fundam Clin Pharmacol 2003, 17:651-658.

27. Nishiguchi S, Shiomi S, Nakatani S, Takeda T, Fukuda K, Tamori A, Habu D, Tanaka T: Prevention of hepatocellular carcinoma in patients with chronic active hepatitis C and cirrhosis. Lancet 2001, 3:196-197.

28. Murata M, Nabeshima S, Kikuchi K, Yamaji K, Furusyo N, Hayashi J: A comparison of the antitumor effects of interferon-alpha and beta on human hepatocellular carcinoma cell lines. Cytokine 2006, 33:121-128.

doi:10.1186/1477-7819-11-240

Cite this article as: Jiang et al:: A meta-analysis and systematic review: adjuvant interferon therapy for patients with viral hepatitis-related hepatocellular carcinoma. World Journal of Surgical Oncology 2013 11:240.

\section{Submit your next manuscript to BioMed Central and take full advantage of:}

- Convenient online submission

- Thorough peer review

- No space constraints or color figure charges

- Immediate publication on acceptance

- Inclusion in PubMed, CAS, Scopus and Google Scholar

- Research which is freely available for redistribution 